
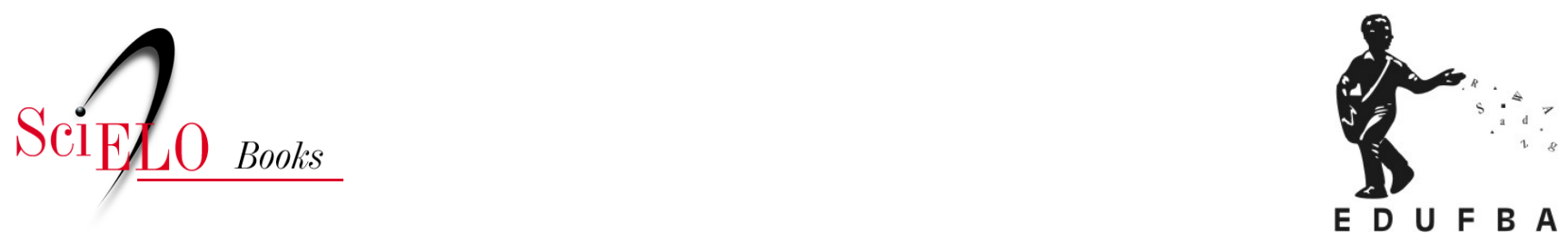

\title{
Parte II - Propostas de ensino \\ Tipos de próteses como tema sociocientífico para a promoção da argumentação no ensino de química
}

\author{
Luciana Passos Sá \\ Salete Linhares Queiroz
}

\section{SciELO Books / SciELO Livros / SciELO Libros}

SÁ, L.P., and QUEIROZ, S.L. Tipos de próteses como tema sociocientífico para a promoção da argumentação no ensino de química. In: CONRADO, D.M., and NUNES-NETO, N. Questões sociocientíficas: fundamentos, propostas de ensino e perspectivas para ações sociopolíticas [online]. Salvador: EDUFBA, 2018, pp. 231-243. ISBN 978-85-232-2017-4. https://doi.org/10.7476/9788523220174.0011.

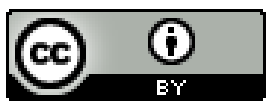

All the contents of this work, except where otherwise noted, is licensed under a Creative Commons Attribution 4.0 International license.

Todo o conteúdo deste trabalho, exceto quando houver ressalva, é publicado sob a licença Creative Commons Atribição 4.0. 


\title{
TIPOS DE PRÓTESES COMO TEMA SOCIOCIENTÍFICO PARA A PROMOÇÃO DA ARGUMENTAÇÃO NO ENSINO DE QUÍMICA
}

\author{
Luciana Passos Sá \\ Salete Linhares Queiroz
}

\section{Introdução}

A Questão Sociocientífica (QSC) discutida neste capítulo e apresentada no formato do caso, denominado Caso das Próteses, trata de uma situação fictícia, porém baseada em histórias reais de pessoas, normalmente vítimas de acidentes, que necessitam recorrer ao uso de próteses para substituir partes do corpo. O caso se mostrou bastante favorável na promoção de argumentos pelos estudantes por exigir, na sua análise e resolução, a consideração de aspectos que vão além daqueles de natureza científica. Questões políticas e éticas ligadas, por exemplo, à investigação de novas tecnologias mais acessíveis à população ou questões de cunho social e/ou econômico, como o custo envolvido nos diferentes tipos de próteses existentes e às diferentes oportunidades de acesso da sociedade a tecnologias que visam à melhoria da qualidade de vida do indivíduo, são aspectos mencionados na argumentação acerca do tema. Também são pontos fortemente enfatizados na análise da QSC envolvida neste caso aspectos mais específicos relacionados aos diferentes tipos de próteses, tais como leveza e maleabilidade dos materiais, biocompatibilidade e recuperação pós-operatória. 
Nesse contexto, o objetivo deste capítulo é apresentar uma QSC, elaborada no formato de um caso, tendo em vista a promoção da argumentação no ensino superior de química. Assim, discutiremos a potencialidade das QSC para a promoção da argumentação no ensino de ciências. Também apresentaremos informações acerca da elaboração de casos e, particularmente, detalharemos características do caso denominado Caso das Próteses e formas de sua aplicação no ensino superior de química.

\section{QSC na promoção da argumentação no ensino de ciências}

A inserção de QSC em ações desenvolvidas, tanto no ensino básico (KOLSTO, 2006; SADLER; DONNELLY, 2006) quanto no superior (SÁ; KASSEBOEHMER; QUEIROZ, 2013; CONRADO; NUNES-NETO; EL-HANI, 2015), tem sido fortemente incentivada, dentre outras razões, pela potencialidade que a discussão a respeito das mesmas apresenta em promover habilidades argumentativas entre os estudantes. Segundo Simonneaux (2008), as QSC, frequentemente referenciadas pela sigla SSI (oriunda da sigla inglesa Socioscientific Issues), são questões controversas em que competem diferentes visões e que têm implicações em um ou mais campos do conhecimento, como a biologia, a sociologia, a ética, a política, a economia, dentre outras.

Campaner e De Longhi (2007) reconhecem o caráter transversal e interdisciplinar envolvido em tais questões e destacam que o propósito fundamental da sua abordagem está relacionado à formação de cidadãos comprometidos socioambientalmente, com capacidade crítica e reflexiva. Nessa perspectiva, estes se tornam aptos a avaliar as informações recebidas, a refletir sobre as atuações próprias e alheias e hábeis para argumentar adequadamente diante das decisões a serem tomadas.

Dentre as estratégias comumente empregadas em propostas com abordagem SSI, algumas têm se destacado nos trabalhos reportados na literatura, como o debate, o role-play e o estudo de caso. O debate está centrado na prática da argumentação (ALTARUGIO; DINIZ; LOCATELLI, 2010) como uma "[...] atividade social discursiva que se realiza pela justificação de pontos de vista e consideração de perspectivas contrárias [contra-argumento] com o objetivo último de promover mudanças nas representações dos participantes sobre o tema discutido". (DE CHIARO; LEITÃO, 2005, p. 350) O role-play consiste em uma atividade que inclui a atribuição de papéis a um ou mais membros de um pequeno grupo, de modo que uma determinada questão seja analisada em diferentes perspectivas. (SIMONNEAUX, 2001) O estudo de caso, por sua vez, é um método que oferece aos estudantes a oportunidade de direcionar a própria aprendizagem e investigar aspectos sociocientíficos presentes em situações reais ou simuladas. São narrativas sobre dilemas vivenciados por indivíduos que necessitam tomar importantes decisões acerca de determinadas questões. A tomada de decisão é normalmente acompanhada de argumentação por aqueles que a tomaram. (SÁ; QUEIROZ, 2009) 
A argumentação pode ser entendida como uma atividade social, intelectual e verbal, empregada quando se pretende justificar ou refutar uma opinião, que consiste em fazer declarações, levando em consideração o receptor e a finalidade com a qual se emitem. Para que haja argumentação, são necessárias a escolha entre diferentes opções ou explicações e a análise dos critérios que permitam avaliar como mais adequada a opção escolhida. (SANMARTÍ, 2003) Segundo Leitão e Almeida (2000), a argumentação não implica necessariamente presença mínima de dois interlocutores. É possível haver argumentação em situações de monólogos, como palestras e textos escritos que, mesmo nessas condições, é ainda o diálogo que estrutura a forma que a argumentação assume. Em tais situações, o diálogo se realiza pela presença de um interlocutor imaginário a quem a argumentação se dirige. O convencimento de outro sujeito é sempre o fim último da argumentação.

Nessa perspectiva, a apresentação de QSC em forma de estudo de caso pode possibilitar o desenvolvimento de habilidades argumentativas no ensino de ciências, além de aumentar o interesse dos estudantes pela aula, a compreensão dos conteúdos envolvidos e a capacidade de comunicação a partir do uso de conhecimentos científicos, aliados a outros tipos de conhecimentos, como aqueles de natureza social, ética, política e econômica.

\section{Elaboração de casos de caráter sociocientífico}

O caso que apresentamos neste capítulo foi elaborado para aplicação no ensino superior de química. Contudo, como se fundamenta na discussão de aspectos sociocientíficos e não apenas de caráter científico, é também conveniente para estudo em outros níveis e cursos. Para tanto, é necessário que sejam estabelecidas relações entre o cenário apresentado no caso e o contexto educacional, de modo a que se fomente o desenvolvimento de habilidades de comunicação oral dos alunos e de busca nas diversas fontes de informação, por exemplo.

Além do Caso das Próteses, mais cinco casos $^{1}$ de mesma natureza foram elaborados de acordo com as recomendações de Herreid (1998) sobre os aspectos a serem considerados na elaboração de um "bom caso", dentre os quais destacamos:

- $\quad$ utilidade pedagógica: deve ser útil para o curso e para os estudantes;

- relevância ao leitor: deve envolver situações que possivelmente os estudantes estejam aptos a compreender e enfrentar;

1 Os casos Praga do Coqueiro, Caso das Próteses, Ameaça nos Laranjais, Poluição em Rondônia e Doença de Granja foram elaborados em conjunto e podem ser encontrados na íntegra, na página do Grupo de Pesquisa em Ensino de Química do Instituto de Química de São Carlos da Universidade de São Paulo (GPEQSC). Disponível em: <http://www.gpeqsc.com.br/casos/arquivos/colecao/ colcaso01.pdf>. 
- interesse pela questão/conflito: para que pareça real, deve descrever um drama, um suspense, uma questão a ser resolvida.

A maioria dos casos é fundamentada sobre um assunto controverso:

- atualidade: deve tratar de questões atuais, que levem o aluno a compreender a importância do assunto;

- extensão: devem ser curtos, suficientes para introduzir os fatos, sem que cause uma análise tediosa;

- empatia com os personagens centrais: as características escolhidas para os personagens devem influenciar na tomada de decisões;

- necessidade de decisão: deve haver urgência e seriedade na resolução dos casos;

- generalizações: deve ter aplicabilidade geral, e não ser específico para uma curiosidade apenas;

- narrativa/diálogos: deve narrar uma história em que o final não exista ainda e incluir diálogos que promovam a empatia dos estudantes com os personagens da história.

Nesse sentido, recomendamos adicionar vida e drama nos diálogos. (SÁ, 2010)

Pesquisas recentes publicadas na revista Pesquisa Fundação de Amparo à Pesquisa do Estado de São Paulo (Fapesp) serviram como fonte de inspiração para a elaboração dos casos. Os casos foram estruturados de modo que apresentassem em seu contexto questões sociais, ambientais, econômicas e/ou éticas, com o intuito de estimular no aluno a capacidade de tomar decisões diante de problemas da vida real e de argumentar a favor das mesmas.

A seguir, discutiremos a argumentação a partir da aplicação do caso denominado Caso das Próteses (Quadro 1), que aborda a situação do jovem João Carlos, vítima de grave acidente de moto, que provocou uma grande fratura no seu maxilar. As sequelas causadas pelo acidente fizeram com que ele ficasse desmotivado e com dificuldades de relacionamento com as outras pessoas. Além disso, o jovem ficou com limitações na realização das funções de falar e mastigar comidas sólidas. A família de João Carlos não possuía recursos financeiros suficientes para busca de tratamento particular e necessitava recorrer ao Sistema Único de Saúde (SUS). Como futuros químicos, cabia aos grupos responsáveis pela resolução do caso ajudar a equipe de médicos a escolher o tipo de prótese mais adequado para João Carlos. 
Quadro 1 - Caso das Próteses

\section{Caso das Próteses}

João Carlos, 23 anos, há dois anos evita sair de casa para ir ao mercado, jogar com os amigos e até procurar emprego. Foi exatamente há dois anos que João foi vítima de um terrível acidente de moto, que acabou resultando em uma grande fratura no seu maxilar. A perda da antiga forma de seu rosto o tornou uma pessoa triste, com baixa autoestima e sem vontade de se relacionar com as outras pessoas. Além disso, João sente dificuldades para falar e mastigar comidas sólidas.

João sempre morou em São Carlos, cursava Física na Universidade de São Paulo (USP), mas abandonou o curso e outras atividades logo após o acidente.

Mariana nunca desistiu de buscar uma solução para o problema de seu único irmão. Foi a hospitais, clínicas, falou com vários médicos, mas a situação era difícil, pois não tinham muitos recursos financeiros. No entanto, depois de várias tentativas frustradas, Mariana conversa com um médico que se mostra disposto a ajudá-la.

Mariana chega em casa eufórica e conversa com os familiares:

- Mamãe, João, venham aqui. Tenho ótimas notícias para vocês.

- O que aconteceu? Pergunta João, sem mostrar muito entusiasmo.

- Dr. Alberto se mostrou muito interessado em nos ajudar. Ele me falou sobre vários tipos de próteses que estão sendo utilizadas em pessoas vítimas de acidentes com armas e carros. Essas próteses substituem ossos da mandíbula, crânio ou face. sua mãe.

- Mas, como iremos pagar uma cirurgia como essa? Deve custar muito caro, comenta Dona Lourdes,

- Dr. Alberto me falou que cirurgias como essas estão sendo feitas pelo SUS, me prometeu falar com alguns amigos seus, especialistas na área, e, junto com eles, pensar em um tipo de prótese adequada para João, explica Mariana.

- Obrigado, minha irmã. Meu maior sonho é ter de volta a antiga forma do meu rosto, fala João.

Dois dias depois, Dr. Alberto liga para Mariana:

- Como vai, Dr. Alberto? Fala Mariana.

- Olá Mariana, tenho ótimas notícias. Conversei com alguns colegas e eles me falaram sobre excelentes próteses utilizadas atualmente, e que irão decidir sobre o tipo mais adequado a ser usado para o caso de João. Falei da situação de seu irmão e eles estão dispostos a operá-lo o mais breve possível. É preciso que ele compareça a uma consulta amanhã, às dez horas, para acertarem tudo, explica Dr. Alberto.

- Muito obrigada, Dr. Alberto. Amanhã estaremos lá.

No dia seguinte, tudo foi acertado e a cirurgia marcada para uma semana depois.

Vocês, como estudantes de Química, ajudarão a equipe de médicos a escolher o tipo de prótese mais adequado para o caso de João Carlos.

Fonte: adaptado de Ereno (2003). 
A partir desse caso, outras questões poderão ser exploradas por professores de outras disciplinas, de acordo com seu contexto. Abaixo, inserimos alguns exemplos, com indicação de algumas áreas correlatas, entre parênteses:

Q1. Onde, quando e em que contexto surgem as próteses? (história e geografia)

Q2. Quais os diferentes tipos de materiais para próteses, seus diferentes usos, suas vantagens e desvantagens? (química e física)

Q3. Há relações entre a implantação de próteses e o aumento da sensação do "membro fantasma" em pacientes? (biologia e psicologia)

Q4. Como acidentes que levam à perda de partes do corpo podem afetar a qualidade de vida de um indivíduo e sua família? (sociologia e psicologia)

Q5. Como a implantação de próteses pode melhorar a autoestima e a qualidade de vida de pacientes? (sociologia e psicologia)

Q6. Quais as políticas públicas do Brasil e os desafios para o acesso a tecnologias como próteses para a população de baixa renda? (sociologia e política)

Q7. Quais as estimativas de oferta e demanda de próteses para a população brasileira? (matemática)

Q8. Os benefícios sociais do desenvolvimento de novas tecnologias para substituição de partes do corpo humano superam os custos socioambientais? (biologia e filosofia)

Q9. As próteses artificiais podem substituir perfeitamente elementos naturais/biológicos humanos? Haveriam implicações morais nessa substituição? (biologia e filosofia)

Q10. Quais as controvérsias envolvidas no uso de tecnologias como próteses para a melhoria ou a recuperação de habilidades humanas, como, por exemplo, no caso da formação de soldados biônicos? (filosofia e política)

\section{Objetivos de aprendizagem (conceituais, procedimentais e atitudinais)}

Com base nos resultados da aplicação deste caso (SÁ, 2010), podemos organizar alguns objetivos de aprendizagem (ZABALA; ARNAU, 2010) para orientar professores de diversas áreas na abordagem do Caso das Próteses:

\section{Conceituais}

- Compreensão de fatos, conceitos e dados associados aos impactos ambientais, sociais e econômicos, como viabilidade, segurança, conforto, qualidade de vida 
do paciente e outras vantagens e desvantagens, relacionados aos diferentes tipos de prótese; histórico de evolução das próteses e seu uso em diferentes contextos, como para vítimas da guerra.

\section{Procedimentais}

- Comparação de diferentes tipos de próteses para o paciente, considerando materiais, custos e resultados; organização e apresentação de argumentos, considerando aspectos científicos, éticos, históricos, políticos, sociais, ambientais, entre outros.

\section{Atitudinais}

- Reflexão sobre problemas burocráticos, de natureza ética e política, relacionados ao SUS brasileiro; questões de negligência médica e irregularidades na prescrição de dispositivos médicos como próteses; dificuldades de acesso a tratamentos médicos de maior qualidade por indivíduos com menores condições financeiras; exclusão social vivenciada por portadores de alguma deficiência física; comportamentos de risco para acidentes, como de trânsito; interesses, custos e benefícios envolvidos no desenvolvimento de tecnologias relacionadas à saúde humana; formas de divulgar informações para a população dos resultados/argumentos encontrados na resolução do caso.

\section{Meios para aplicação e discussão da QSC no ensino}

Para a resolução do caso pelos alunos, recomendamos a formação de grupos, constituídos de três a cinco participantes. Antes do início do trabalho com o caso, os alunos deverão ser orientados sobre as possíveis maneiras de proceder para a sua resolução e tomar conhecimento do Guia para a Análise e Resolução dos Casos (Quadro 2). Este tem o objetivo de auxiliá-los na discussão e na análise dos problemas apresentados no caso. É recomendável também solicitar aos alunos que pesquisem individualmente, nas diversas fontes, informações sobre os assuntos envolvidos no caso e que tragam os resultados das pesquisas para os próximos encontros. Nos encontros, para os quais sugerimos uma duração planejada para duas horas cada, os alunos poderão responder, por escrito, questões relacionadas ao caso, elaboradas tomando por base o Modelo Normativo de Tomada de Decisão de Kortland (1996), que evidencia etapas capazes de: organizar as informações coletadas a respeito do problema; refletir e comparar alternativas de solução do problema; e facilitar a tomada de decisão pelos alunos e posterior argumentação (Figura 1). 
Quadro 2 - Guia para a análise e resolução dos casos

\section{Os estudantes devem considerar os seguintes itens após a leitura:}

1- Reconhecer assuntos em potencial. Listar termos ou frases que pareçam ser importantes para compreensão do assunto que o caso aborda.

2- Fazer levantamento de conexões por meio de tempestade mental. Discutir sucintamente com seu grupo o seguinte:

- Sobre o que é o caso?

- Quais são os temas principais do caso?

Para organizar melhor o seu trabalho, tome nota dos assuntos e perguntas pricipais que surgirem na tabela abaixo:

\begin{tabular}{|l|l|}
\hline O que nós sabemos sobre o caso? & O que nós ainda precisamos saber para solucionar o caso? \\
\hline & \\
& \\
\hline
\end{tabular}

3- Obter fontes ou referências adicionais para ajudar a responder ou explorar as perguntas. Estas podem conter materiais impressos, artigos, banco de dados, resultados de simulações, mapas etc. Sejam criativos na procura de informações.

4- Projetar e conduzir investigações científicas relevantes para as perguntas. Estas podem utilizar métodos laboratoriais, pesquisa de campo apropriada (entrevista com especialistas da área), computadores com módulos de software, gráficos etc.)

5- Produzir material que demonstre o entendimento das conclusões. Fazer uma apresentação em Power Point ou Open Office e escrever um artigo nos moldes apresentados na revista Eletrônica do CDCC (revista@cdcc.sc.usp.br). Esses materiais devem servir para persuadir os colegas de suas ideias e evidenciar a compreensão das suas conclusões.

Fonte: Sá (2010, p. 274).

Figura 1 - Modelo normativo de tomada de decisão de Kortland (1996)

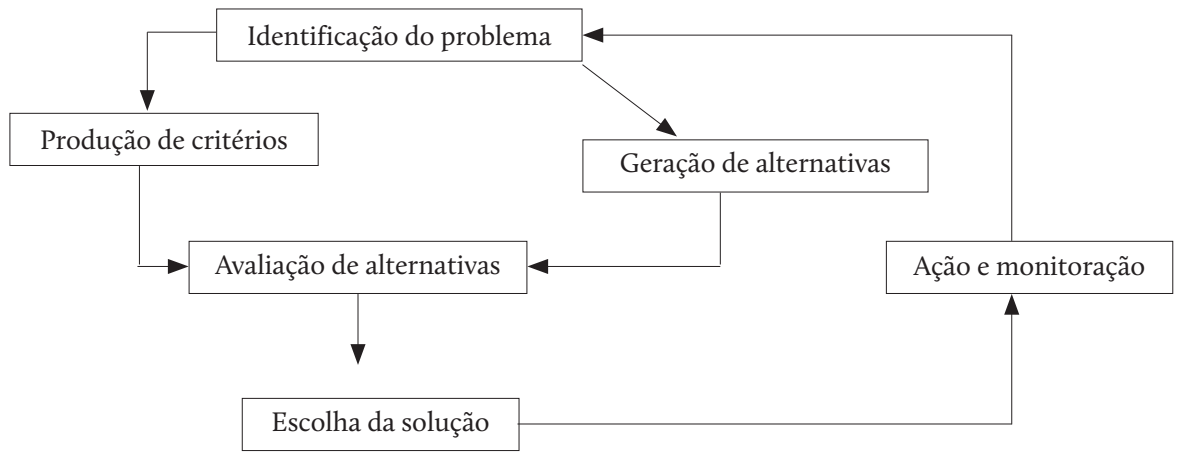

Fonte: Sá (2010, p. 76). 
Também sugerimos a produção de um diário do caso, que deverá deixar claro ao leitor o processo que conduzirá o grupo à resolução do caso, incluindo informações obtidas no processo e reflexões sobre o seu andamento. Um texto sobre a situação envolvida no caso estudado, com formato de linguagem voltada para o ensino médio ou para a comunidade não acadêmica, também poderá ser produzido pelos alunos. A resolução dos casos deverá ser apresentada por cada grupo, em um período de aproximadamente 20 minutos. Após a realização das exposições orais, um debate pode ser promovido entre os grupos. Experiências reportadas na literatura indicam que a argumentação é mais profícua quando o debate é promovido entre grupos que se dedicaram à resolução de um mesmo caso. (SÁ, 2010)

A segunda perspectiva que consideramos para a aplicação da QSC consiste na explicitação das fontes de evidências empregadas pelos grupos como forma de garantir confiabilidade às informações fornecidas. Desse modo, os enunciados podem ser classificados como evidências pessoais ou de autoridade, de acordo com as suas fontes. (KIM; SONG, 2005) Algumas fontes de evidências poderão ser identificadas nas apresentações orais dos grupos, como evidências de autoridade por especialistas e instituições, evidências pessoais, entre outras. O professor pode orientar os estudantes quanto à avaliação da confiabilidade das fontes de informação, durante o processo investigativo realizado pelos estudantes.

Por fim, para a análise dos argumentos dos alunos, recomendamos o uso do modelo de Toulmin (2001), com posterior aplicação de metodologia proposta por Erduran, Simon e Osborne (2004).

O primeiro, ilustrado na Figura 2, permite a análise dos argumentos elaborados pelos estudantes do ponto de vista estrutural, ou seja, pela distinção entre os diferentes componentes que constituem um argumento, assim como as relações existentes entre eles. O modelo, além de mostrar o papel das evidências na elaboração de afirmações, relacionando aos dados e conclusões por meio de justificativas, também realça as limitações de uma dada teoria, bem como sua sustentação em outras teorias. (SÁ, 2010)

Figura 2 - Modelo de Toulmin.

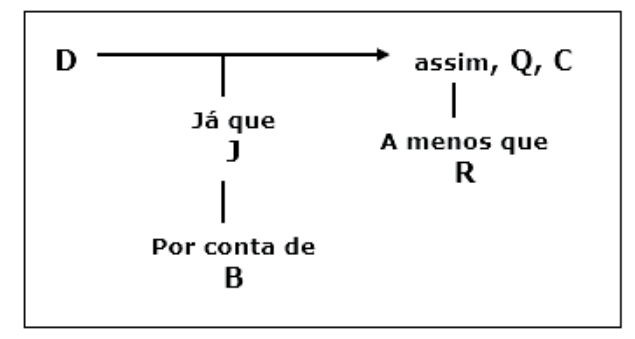

Fonte: Toulmin (2001, p. 150). 
Segundo Toulmin (2001), os elementos fundamentais de um argumento são: o dado (D), a conclusão (C) e a justificativa (J). É possível apresentar um argumento contando apenas com esses elementos. Porém, para que um argumento seja completo, pode-se especificar em que condições a justificativa apresentada é válida ou não, indicando um peso para tal justificativa. Desta forma, podem ser acrescentados ao argumento qualificadores modais $(\mathrm{Q})$, ou seja, especificações das condições necessárias para que uma dada justificativa seja válida. Da mesma forma, é possível especificar em que condições a justificativa não é válida ou suficiente para dar suporte à conclusão. Neste caso, é apresentada uma refutação (R) da justificativa. Além dos elementos já citados, a justificativa, que apresenta um caráter hipotético, pode ser apoiada em uma alegação categórica baseada em uma lei, por exemplo. Trata-se de uma alegação que dá suporte à justificativa, denominada backing (B) ou conhecimento básico. Uma descrição detalhada de cada um desses componentes, assim como uma visão geral a respeito do respectivo modelo, pode ser encontrada no livro Os usos do argumento. (TOULMIN, 2001)

A metodologia proposta por Erduran, Simon e Osborne (2004) sugere que a qualidade dos argumentos é avaliada a partir da observação da combinação dos componentes do argumento, segundo Toulmin (2001), nas falas/textos escritos produzidos pelos estudantes. Ou seja, as combinações que possuem um maior número de componentes são típicas de um argumento mais bem elaborado. Assim, um argumento que apresenta "conclusão, dado e justificativa" é menos sofisticado do que outro que tem apenas "conclusão, dado, justificativa e refutação".

\section{Estratégias de aprendizagem}

A psicologia cognitiva baseada na Teoria do Processamento da Informação tem concentrado seus esforços em esclarecer como os seres humanos adquirem, armazenam e utilizam as informações. Adeptos dessa visão destacam a importância de se transcender o ensino dos fatos e de se assegurar a apropriação, por parte dos estudantes, dos processos psicológicos pelos quais se aprendem os fatos. Neste contexto, eles acreditam no ensino de estratégias de aprendizagem como um caminho frutífero em direção à autorregulação da aprendizagem. (BORUCHOVITCH, 2007)

Nesse sentido, recomendamos analisar as estratégias de aprendizagem empregadas pelos alunos no processo de resolução do caso e verificar em que medida o caso proposto estimula determinados tipos de estratégias pelos estudantes. Para tanto, quatro tipos de estratégias podem ser consideradas: cognitivas, metacognitivas, sociais e afetivas. De acordo com Dembo (1994), as estratégias cognitivas operam diretamente sobre o material a ser aprendido, auxiliando o estudante a melhor processar a informação, enquanto que as metacognitivas são procedimentos que o indivíduo emprega para planejar, monitorar e regular o seu próprio pensamento e ação. Paiva (1998) define as estratégias sociais como aquelas que promovem a interação e a cooperação de uns com os outros, e 
as afetivas como aquelas que envolvem o controle das emoções, das atitudes, dos valores e da motivação.

\section{Considerações finais}

Neste capítulo, discutimos acerca de uma proposta de ensino baseada no emprego de casos de caráter sociocientífico e como esta pode favorecer o desenvolvimento de habilidades argumentativas. Casos, como o aqui apresentado, não são produzidos de forma aleatória, mas com base em orientações sobre os aspectos desejáveis em uma narrativa sociocientífica, quando se pretende trabalhar conteúdos específicos ou estimular determinados tipos de habilidades. Simonneaux (2008), por exemplo, sinaliza que o conhecimento envolvido nas QSC não deve ser simplesmente controverso, mas deve também abarcar uma pluralidade de disciplinas. O contexto do problema e os campos das disciplinas envolvidas devem ser definidos de modo a construir uma situação propícia ao debate, em que a argumentação sobre a questão não envolva somente o conteúdo, mas também dimensões sociais e valores pessoais. Nesse sentido, o caso proposto contempla as recomendações supracitadas e pode ser adaptado em situações nas quais o professor deseje estimular o pensamento crítico dos estudantes acerca de questões dessa natureza.

Também vale destacar que, embora o foco da proposta tenha sido o desenvolvimento da argumentação, esta também se mostra favorável à aprendizagem de conceitos científicos e à melhor compreensão acerca da natureza da construção do conhecimento científico. Adaptações à proposta se mostram pertinentes, de acordo com os objetivos do professor e o nível de ensino, sendo plausível a inserção de ações como esta no ensino fundamental e médio. Tais ações contemplam aspectos importantes na formação do estudante, como o desenvolvimento do pensamento crítico e da expressão oral e escrita, assim como da capacidade de trabalhar em grupo. Nessa perspectiva, é considerável a potencialidade das mesmas para a formação de um cidadão capaz de organizar seus conhecimentos para a resolução de problemas sociais e ambientais.

\section{Referências}

ALTARUGIO, M. H.; DINIZ, M. H.; LOCATELlI, S. W. O debate como estratégia em aulas de química. Química Nova na Escola, São Paulo, v. 32, n. 1, p. 26-30, 2010.

BORUCHOVITCH, E. Aprender a aprender: propostas de intervenção em estratégias de aprendizagem. Educação Temática Digital, Campinas, v. 8, n. 2, p. 156-167, 2007.

CAMPANER, G.; DE LONGHI, A. L. La argumentación en educación ambiental. Una estrategia didáctica para la escuela media. Revista Electrónica de Enseñanza de las Ciencias, Ourense, v. 6, n. 2, p. 442-456, 2007. 
CONRADO, D. M.; NUNES-NETO, N. F.; EL-HANI, C. N. Argumentação sobre problemas socioambientais no ensino de biologia. Educação em Revista, Belo Horizonte, v. 31, n. 1, p. 329-357, 2015.

DE CHIARO, S.; LEITÃO, S. O papel do professor na construção discursiva da argumentação em sala de aula. Psicologia: Reflexão e Crítica, Porto Alegre, v. 18, n. 3, p. 350-357, 2005.

DEMBO, M. H. Applying educational psychology. New York: Longman, 1994.

ERENO, D. Próteses de mamona. Pesquisa Fapesp, São Paulo, n. 91, p. 66-71, 2003.

ERDURAN, S.; SIMON, S.; OSBORNE, J. Tapping into argumentation: developments in the application of Toulmin's argument pattern for studying science discourse.

Science Education, New York, v. 88, n. 6, p. 915-933, 2004.

HERREID, C. F. What makes a good case? Journal of College Science Teaching, [S.1.], v. 27, n. 3, p. 163-169, 1998.

KIM, H.; SONG, J. The features of peer argumentation in middle school students' scientific inquiry. Research in Science Education, Amsterdam, v. 36, n. 3, p. 211-233, 2005.

KOLSTO, S. D. Patterns in student's argumentation confronted with a risk-focused socio-scientific issue. International Journal of Science Education, London, v. 28, n. 14, p. 1689-1716, 2006.

KORTLAND, K. An STS case study about students' decision making on the waste issue. Science Education, New York, v. 80, n. 6, p. 673-689, 1996.

LEITÃO, S.; ALMEIDA, E. G. S. A produção de contra-argumentos na escrita infantil. Psicologia: Reflexão e Crítica, Porto Alegre, v. 13, n. 3, p. 351-361, 2000.

PAIVA, V. L. M. O. Estratégias individuais de aprendizagem de língua inglesa. Letras e Letras, Uberlândia, v. 14, n. 1, p. 73-88, 1998.

SADLER, T. D.; DONNELLY, L. A. Socioscientific argumentation: the effects of content knowledge and morality. International Journal of Science Education, London, v. 28, n. 12, p. 1463-1488, 2006.

SÁ, L. P. Argumentação no ensino superior de química: investigando uma atividade fundamentada em estudo de casos. 2006. 152 f. Dissertação (Mestrado em Química) Instituto de Química São Carlos, Universidade de São Paulo, São Paulo, 2006.

SÁ, L. P. Estudo de casos na promoção da argumentação sobre questões sócio-científicas no ensino superior de química. 2010. 278f. Tese (Doutorado em Química) - Universidade Federal de São Carlos, São Carlos, 2010.

SÁ, L. P.; QUEIROZ, S. L. Estudo de casos no ensino de química. Campinas: Átomo, 2009. 
SÁ, L. P.; KASSEBOEHMER, A. C.; QUEIROZ, S. L. Casos investigativos de caráter sociocientífico: aplicação no ensino superior de química. Educación Química, México, v. 24, n. 2, p. 522-528, 2013. Suplemento.

SANMARTí, N. Aprende ciéncies tot aprenent a escriture ciéncie. Barcelona: Centres de recuros pedagògics de laciutat de Barcelona, 2003.

SIMONNEAUX, L. Argumentation in socio-scientific contexts. In: ERDURAN, S., JIMENEZ-ALEIXANDRE, M. P. (Ed.). Argumentation in Science Education: Perspectives from classroom-based research. Dordrecht: Springer, 2008. p. 179-199.

SIMONNEAUX, L. Role-play or debate to promote students' argumentation and justification on an issue in animal transgenesis. International Journal of Science Education, London, v. 23, n. 9, p. 903-927, 2001.

TOULMIN, S. Os usos do argumento. Tradução de Reinaldo Guarany. São Paulo: Martins Fontes, 2001.

ZABALA, A.; ARNAU, L. Como aprender e ensinar competências. Porto Alegre: Artmed, 2010. 